\title{
THE FREE ENERGY OF AQUEOUS SULFURIC ACID.
}

Thesis

by

Joseph E.Mayer.

In partial fulfillment of the requirements for the degree of Bachelor of Science in Chemistry,

California Institute of Technology Pasadena, California. 


\section{Previous Work and Outline of this Investigation}

Though aqueous sulfuric acid is one of the most important acids, its free energy and its oxidizing power are very imperfectly known. In concentrated solution, especially when hot, sulfuric acid is strongly oxidizing while in dilute solution it oxidizes scarcely any of even the most strongly reducing substances.

The researches which may be used for calculating the free energy of aqueous sulfuric acid have recently been briefly discussed by Lewis and Randall. ${ }^{2}$ The equilibria studied, however, were such that it is necessary to approximate the fugacities of the gases and the activities of the liquids involved, and to recalculate the results to standard temperature, which involves the use of uncertain heat data and a rather large extrapolation. Lewis and Randall ${ }^{2}$ nevertheless give $-176,500$ calories as a"provisional value". for the free energy of $1 \mathrm{H}_{2} \mathrm{SO}_{4}$ at $25^{\circ}$ at hypothetical 1 molal.

The determinations here presented are based upon measurements of the equilibrium in aqueous solution at $80^{\circ}$ of the reaction, $\mathrm{H}_{2} \mathrm{SO}_{4}+6 \mathrm{HI}=$ $3 \mathrm{I}_{2}+4 \mathrm{H}_{2} \mathrm{O}+\mathrm{S}_{\mathrm{rh}}$. Equilibrium was attained with sulfuric acid at 5-7 $M$, hydriodic acid at $0.4-1.0 M$, and iodine at $0.04-0.3 M$. The concentrations of hydrogen iodide and iodine were kept as small as possible in comparison to that of the sulfuric acid, so that their presence would not largely change its activity. The reaction proceeds from either side

1 National Research Fellow in Chemistry.

${ }^{2}$ Lewis and Randall, "Thermodynamics," McGraw-Hill Book Co., N. Y., 1923, pp. $552-555$.

(Work done in conjunction with Dr. D.F.Smith

$$
\text { at this laboratory) }
$$


. of the equilibrium at a rather slow rate even at a temperature of $80^{\circ}$, but equilibrium is nearly attained within a few weeks.

The difierence in the free energies of the hydrogen iodide and iodine in the equilibrium solutions was determined by measuring the electromotive force of half-cells containing those solutions in contact with a platinum electrode and connected with a hydrogen-gas half-cell containing sulfuric acid and hydrochloric acid (in place of hydriodic acid) at the same concentrations.

The reaction accompanying the passage of 6 faradays throtigh the cell is $3 \mathrm{H}_{2}(\mathrm{~g})+3 \mathrm{I}_{2}$ (in the equilibrium solution) $=6 \mathrm{HI}$ (in the equilibrium solution). Its electromotive force therefore gives a direct measure of the difference in the free energies of the hydrogen iodide and iodine in the equilibrium solution; and, hence, also of the equal change in free energy attending the reaction, $3 \mathrm{H}_{2}(\mathrm{~g})+\mathrm{H}_{2} \mathrm{SO}_{4}=4 \mathrm{H}_{2} \mathrm{O}+\mathrm{S}_{\mathrm{rh}}$, taking place under the conditions of concentrations prevailing in the equilibrium mixtures. The known vapor pressures of water over sulfuric acid solutions at $80^{\circ}$ enabled the ratios of the activities of the water and hence of the sulfuric acid in the various equilibrium solutions to be calculated. And finally, by means of known heats of formation, heats of solution, and specific heats, the results could be recalculated to the standard temperature of $25^{\circ}$.

'The authors are greatly indebted to Professor A. A. Noyes, the director of this Iaboratory, for several valuable suggestions with regard to the experimental work, and especially for his criticism of our presentation of the data for publication.

\section{Procedure in Making the Equilibrium Measurements}

It was found that the hydriodic acid of commerce contains a small amount of some substance which immediately reduces sulfuric acid to hydrogen sulfide without formation of iodine. This substance is probably phosphonium iodide, which is formed during the process of manufacture by the phosphorus method. We therefore prepared all our hydriodic acid by direct combination of the pure elements as described by Bodenstein. ${ }^{3}$

Sulfur was made by acidifying a solution of pure sodium thiosulfate. The amorphous sulfur thus obtained was melted, cooled, and crystallized from carbon disulfide, from which it separated in the form of small erystals of rhombic sulfur.

Sulfur and iodine form liquid solutions; but it was found possible to keep the concentration of iodine in the aqueous solution low enough to avoid liquefaction of the sulfur.

The solutions for the equilibrium measurements were made up from weighed quantities of sulfuric and hydriodic acids standardized through an alkali solution against constant-boiling hydrochloric acid made according to Foulk and Hollingsworth. ${ }^{4}$ The solutions were placed in sealed glass tubes, the air being carefully displaced by carbon dioxide. These tubes were rotated at $80^{\circ}$ on a horizontal shaft in a thermostat containing water covered with a layer of paraffin wax to prevent excessive evaporation. 'The iodine in the equilibrium mixtures was determined by titration against thiosulfate in the usual manner. The results were checked in some cases by titration of the total iodide by

${ }^{3}$ Bodenstein, Z. physik. Chem., 13, 56 (1894).

4 Foulk and Hollingsworth, This JouRNaL, 45, 1220•(1923). 
the method of MeLean and Van Slyke. From the original concentrations and the change in the iodine concentrations the equilibrium concentrations of all the substances present were calculated.

The equilibrium tubes were provided with two sealed-on outlet tubes. Through one of these was passed a slow stream of carbon dioxide while the solutions were being introduced and while the sampie for analysis was quickly removed by means of a pipet filled with carbon dioxide, and discharged into a weighed flask containing a considerable volume of cold water. The flask containing the sample was weighed again to determine the weight of the sample, the solution neutralized with the proper amount of sodium bicarbonate, and immediately titrated with thiosulfate.

\section{Results of the Equilibrium Measurements}

The time of rotation in the thermostat at $80^{\circ}$ and the composition of the equilibrium mixtures are shown in Table I. In the first and fourth experiments the equilibrium was approached from the sulfur side; in the second and third from the sulfuric acid side. The first experiment was made in the early part of the work when great care was not taken to exclude air and is obviously not at equilibrium. The last three solutions represent our best experiments.

\section{TABLE I}

\section{COMPOSITTON OF THE EQUILIRRIUM SOLUTTONS}

$\begin{array}{ccccc}\text { Expt. } & \begin{array}{c}\text { Days } \\ \text { rotated }\end{array} & \mathrm{I}_{2} & \text { Moles per } \mathrm{kg} . \text { of water- } & \text { HISO } \\ 1 & 35 & 0.3110 & 0.8537 & 5.523 \\ 2 & 21 & .1403 & 0.7592 & 5.441 \\ 3 & 21 & .0403 & 0.4492 & 5.886 \\ 4 & 22 & .2767 & 1.0063 & 6.811\end{array}$

\section{Procedure for the Electromotive-Force Measurements}

Measurements were made at $80^{\circ}$ of the electromotive force of cells of the type, $\mathrm{Pt}+\mathrm{H}_{2}(\mathrm{~g})\left|\mathrm{H}_{2} \mathrm{SO}_{4}\left(c_{1}\right)+\mathrm{HCl}\left(c_{2}\right)\right| \mathrm{H}_{2} \mathrm{SO}_{4}\left(c_{1}\right)+\mathrm{HI}\left(c_{2}\right)+\mathrm{I}_{2}\left(c_{3}\right) \mid \mathrm{Pt}$. The solutions in the second half-cell were separately made up of the same composition as the equilibrium solutions, but without sulfur, in a nitrogen-filled tube, the iodide and sulfuric acid solutions not being mixed, bowever, until they had been brought to $80^{\circ}$. The hydrochloric acid in the former half-cell was introduced at the same concentration in moles per $1000 \mathrm{~g}$. of water as was the hydriodic acid in the iodine half-cell, for the purpose of reducing liquid potentials. Moreover, since the sulfuric acid was at the same concentration in the two half-cells, and since it carried most of the current, the liquid potential is doubtless negligible.

The cells were kept in an oil thermostat at $80^{\circ}$. The hydrogen halfcell and saturator were of the type described by Smith and Wonds. ${ }^{6}$ The iodine half-cell consisted of a tube fitted with a glass stopper carrying a piece of smooth platinum foil connected with a mercury cup through a sealed-in platinum wire. It was found that these iodine solutions slowly

5 McLean and Van Slyke, This Journal, 37, 1128 (1915).

S Smith and Woods, izid., 45, 2632 (1923). 
dissolved platinum black from platinized electrodes, the cells giving low readings. This may explain the low results obtained by Stegmuller ${ }^{7}$ on iodine-iodide cells at the higher temperatures. No trouble was experienced with smooth platinum, however.

The cells came to equilibrium in about two hours, after which the electromotive force did not vary more than $0.1 \mathrm{mv}$. for many hours.

The measurements of the cell containing $6.811 M$ sulfuric acid were erratic, and obviously gave too low values. This led to the conclusion that the sulfuric acid had reached a concentration where it was being reduced by the hydrogen in the hydrogen half-cell at an appreciable rate. The electromotive force corresponding to this acid content was consequently obtained by using $5.500 M$ sulfuric acid (in place of $6.811 M$ ) in the hydrogen half-cell and correcting for this difference in concentration, in a manner to be described later, with the aid of the electromotive force of the following cell, which measurements showed to have at $80^{\circ}$ the value 0.0112 volt: $\mathrm{Hg}(1)+\mathrm{Hg}_{2} \mathrm{SO}_{4}(\mathrm{~s})\left|\mathrm{H}_{2} \mathrm{SO}_{4}(6.811 M)\right| \mathrm{H}_{2} \mathrm{SO}_{4}(5.500 M) \mid \mathrm{Hg}_{2} \mathrm{SO}_{4}(\mathrm{~s})+\mathrm{Hg}(1)$.

\section{Results of the Electromotive-Force Measurements}

The results of the electromotive-force measurements are presented in Table II. The measurement upon the first solution is presented merely for the sake of completeness, since the last three solutions represent, as mentioned above, the most reliable results. The concentrations of the substances in the two half-cells are given in moles per $1000 \mathrm{~g}$. of water. The yapor pressure, $p_{\mathrm{w}}$, of water over the solution in the iodine half-cell was taken equal to that in a sulfuric acid solution at $80^{\circ}$ of the same concentration, as determined by Burt. ${ }^{-}$The pressure, $P \mathrm{H}$, of hydrogen in the hydrogen half-cell was found by subtracting the so-obtained vapor-pressure of the water from the barometric pressure. The last column of the table gives the electromotive force corrected to a hydrogen pressure of one atmosphere by adding $(R T / 2 \mathrm{~F}) \cdot \ln (760 / \mathrm{PH})$.

\section{TABLE II}

\begin{tabular}{|c|c|c|c|c|c|c|c|c|c|}
\hline \multirow[b]{2}{*}{ Cell } & \multicolumn{8}{|c|}{ OBSERVED ELECTROMOTIVE FORCES AT $80^{\circ}$} & \multirow{2}{*}{ E.m.f. } \\
\hline & 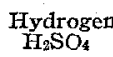 & $\begin{array}{l}\text { half-cell } \\
\mathrm{HCl}\end{array}$ & $\begin{array}{l}\text { Todine } \\
\mathrm{H}_{2} \mathrm{SO}_{4}\end{array}$ & $\begin{array}{r}\text { alf-cell } \\
\text { HI }\end{array}$ & $\mathrm{I}_{2}$ & $\begin{array}{l}\text { E.m.f. } \\
\text { obs. }\end{array}$ & $p_{W}$ & $P_{\text {I }}$ & \\
\hline 1 & 5.523 & 0.8537 & 5.523 & 0.8537 & 0.3110 & 0.3576 & 247.6 & 492.3 & 0.3642 \\
\hline 2 & 5.441 & 0.7592 & 5.441 & 0.7592 & .1403 & .3486 & 249.5 & 487.9 & .3553 \\
\hline 3 & 5.886 & 0.4492 & 5.886 & 0.4492 & .0403 & .3475 & 239.2 & 489.7 & .3542 \\
\hline 4 & 5.500 & 1.0063 & 6.811 & 1.0063 & .2767 & .3475 & 218.2 & 489.7 & .3542 \\
\hline $4 a$ & 6.811 & 1.0063 & 6.811 & 1.0063 & .2767 & (. .3539) & 218.2 & 489.7 & .3606 \\
\hline
\end{tabular}

The electromotive force of Cell 4 in Table II may now be corrected for the difference in the concentration of the sulfuric acid in the hydrogen half-cell and that in the equilibrium solution in Expt. 4 in Table I. When

7 Stegmüller, Z. Elektrochem., 16, 85 (1910).

8 Burt, J. Chem. Soc., 85, 1339 (1904). 
two faradays are passed from left to right through the mercirous sulfate cell formulated above, the cell reaction is the transfer of $T_{I I}$ formula weights of sulfuric acid from the $6.811 M$ to the $5.500 M$ solution, $T_{H}$ being the average transference number of the hydrogen ion for the two solutions. On the other hand, when two faradays are passed through the cell; $\mathrm{H}_{2}(1$ atm. $)\left|\mathrm{H}_{2} \mathrm{SO}_{4}(6.811 M), \mathrm{H}_{2} \mathrm{SO}_{4}(5.500 M)\right| \mathrm{H}_{2}$ (1 atm.) there are so transferred $\left(1-T_{H}\right)$ formula weights of sulfuric acid. The electromotive force of the hydrogen cell therefore stands to that of the mercury cell in the ratio $\left(1-T_{\mathbf{H}}\right) / \mathrm{T}_{\mathbf{H}}$, and the former value could be computed from the latter if the value of $T_{\mathbf{H}}$ were known. This value can, however, be derived from the activity values obtained below and recorded in Table III; for from the activities $a_{1}$ and $a_{2}$ of the sulfuric acid in the $6.811 \mathrm{M}$ and $5.500 \mathrm{M}$ solutions, through the relation $-\Delta F=R T \ln \left(a_{1} / a_{2}\right)$, there can be derived the free-energy decrease $-\Delta F$ attending the transfer of $1 \mathrm{H}_{2} \mathrm{SO}_{4}$ from the first to the second solution. This free-energy value is found to be 3390 joules, which corresponds to 0.0176 volt (since $-\Delta F=2 \mathrm{EF}$ ). Since the electromotive force of the mercury cell was 0.0112 volt, the value of $T_{H}$ is 0.636 , and the electromotive force of the hydrogen-cell formulated above is $364 / 636$ times that of the mercury cell, or 0.0064 volt. If it be assumed that this electromotive force would not be substantially altered by the presence of the relatively small and equivalent quantities of hydrochloric and hydriodic acids in the two sulfuric acid solutions, we shall evidently get the electromotive force of Cell $4 \mathrm{a}$, for which the compositions are recorded in the last row of Table II, by adding this value $(0.0064$ volt $)$ to the electromotive force of Cell 4 in that table. In this way the value 0.3606 , recorded as the corrected electromotive force of Cell $4 \mathrm{a}$, was computed.

\section{Calculation of the Free Energies at $80^{\circ}$}

The relative activities of sulfuric acid at the concentrations involved may first be calculated from the vapor-pressure measurements of Burt at $80^{\circ}$ with the aid of the Duhem equation. This equation leads ${ }^{9}$ to the following expression for the relation between the activities $a_{1}$ and $a_{2}$ of the sulfuric acid and the vapor pressures $p_{1}$ and $p_{2}$ of the water in two solutions, and the mole-ratio $n$ of the water to the acid in any solution:

$$
\log \frac{a_{2}}{a_{1}}=\int_{b_{2}}^{p_{1}} n d \log p
$$

The integration was carried out graphically by plotting $n$ against $\log$ $p / p_{0}$ (where $p_{0}$ is the vapor pressure of pure water), and measuring with a planimeter the area below the graph. The restuts are shown in Table III. The concentrations of sulfuric acid are here given in moles per $1000 \mathrm{~g}$. of water.

Ref. 2, p. 332 . 
TABLE III

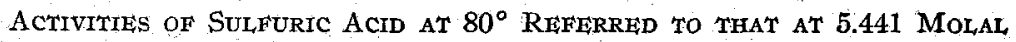

$\begin{array}{lllllll}\text { Molality } \ldots \ldots \ldots \ldots & 3.500 & 4.000 & 4.5000 & 5.000 & 5.441 & 5.500 \\ \text { Activity } \ldots \ldots \ldots \ldots & 0.1328 & 0.2347 & 0.3993 & 0.6580 & 1.000 & 1.065 \\ \text { Molality } \ldots \ldots \ldots \ldots & 5.523 & 5.886 & 6.000 & 6.500 & 6.811 & 7.000 \\ \text { Activity } \ldots \ldots \ldots \ldots & 1.086 & 1.524 & 1.538 & 2.363 & \mathbf{3} .373 & 4.018\end{array}$

* In order to compare the results of the four combinations of equilibrium and electromotive-force measurements, and to derive from them a best average value, we will calculate from each of them the free-energy decrease attending the change in state' (corresponding to Expt. 2 of Table I, and Cell 2 of Table II) expressed by the equation, $3 \mathrm{H}_{2}$ ( $1 \mathrm{~atm}$.) $+\mathrm{H}_{2} \mathrm{SO}_{4}$ $(5.441 M)=4 \mathrm{H}_{2} \mathrm{O}\left(249.5 \mathrm{~mm}\right.$.) $+\mathrm{S}_{\mathrm{rh}}$. To do this we multiply the "corrected electromotive forces" given in the last column of Table II by $6 \times 96,494 / 4.182$; and subtract from the resulting free energies in calories the values of the expressions $R T \ln a$ and $-4 R T \ln \left(p_{\mathrm{w}} / 249.5\right)$, using for $a$ the values of the activities of sulfuric acid given in Table III and for $p_{w}$ the values of the vapor pressure of water given in Table II.

There are thus obtained the following free energies in calories for the change in state as just formulated at $80^{\circ}: 50,340 ; 49,188 ; 48,621 ; 48,692$.

It may be recalled that in the first and fourth experiments the equilibrium was approached from the sulfur side, which would tend to make the calculated free energy too high, and in the second and third experiments, from the sulfuric acid side, which would have the opposite effect. The direction of the deviation of the first value corresponds to the conclusion stated above that in the first experiment equilibrium was probably not fully attained. We adopt, therefore, the mean of the last three values, namely, 48,830 calories, as the best final value.

Using the temperature function for the free energy of water vapor given by Lewis and Randall, ${ }^{10}$ the free energy of $1 \mathrm{H}_{2} \mathrm{O}(\mathrm{g})$ at one atm. and at $80^{\circ}$ is found to be $-53,889$ cal. Subtracting from this the amount $R T$ In $(760 / 249.5)$, the free energy of $1 \mathrm{H}_{2} \mathrm{O}\left(249.5 \mathrm{~mm}\right.$.) at $80^{\circ}$ is found to be $-54,671$ cal. Multiplying this value by four and adding to it 48,830 cal. as derived above, gives $-169,854 \mathrm{cal}$. which is the free-energy decrease accompanying the following reaction at $80^{\circ}: \mathrm{H}_{2} \mathrm{SO}_{4}$ (at $5.441 M$ ) $=$ $\mathrm{H}_{2}$ (1 atm.) $+2 \mathrm{O}_{2}(1 \mathrm{~atm})+.\mathrm{S}_{\mathrm{th}}$ and is thus the free energy content of $1 \mathrm{H}_{2} \mathrm{SO}_{4}$ in $5.441 \mathrm{M}$ solution at $80^{\circ}$. With the aid of the activity ratios at round concentrations presented in Table III the free-energy values for sulfuric acid at these concentrations can be readily calculated.

\section{Calculation of the Free Energies at $25^{\circ}$}

Probably the best value for the heat of formation of sulfuric acid from its elements is that obtained from the data quoted by Bichowsky, ${ }^{11}$. who

${ }^{10}$ Ref. 2 , p. 485.

${ }^{11}$ Bichowsky, THIS JournaI, 44, 130, 131 (1922). 
has reviewed the best thermochemical data. Using these data, the increase in heat content $\Delta H$ for the reaction $2 \mathrm{H}^{+}+\mathrm{SO}_{4}=$ (at infinite dilution $)=\mathrm{H}_{2}(1 \mathrm{~atm})+.2 \mathrm{O}_{2}(1 \mathrm{~atm}$. $)+\mathrm{S}_{\mathrm{rh}}$ is found to be 209,790 cal. at $291^{\circ} \mathrm{K}$. If there is added to this heat effect that for the change in state $\mathrm{H}_{2} \mathrm{SO}_{4}$ (at $\left.5.441 M\right)=2 \mathrm{H}^{+}+\mathrm{SO}_{4}{ }^{*}$, which by interpolation of the data compiled by Lewis and Randall ${ }^{12}$ is found to be -7170 cal., there is obtained the value 202,620 cal., which is the sum of the increases in heat content for the removal of $1 \mathrm{H}_{2} \mathrm{SO}_{4}$ from an infinite quantity of its $5.441 \mathrm{M}$ solution, and the dissociation of it into its elements at $291^{\circ} \mathrm{K}$. This quantity (202,620 cal.) is then the value of $\Delta H$ for the reaction for which we have the free-energy change at $80^{\circ}$, namely for $\mathrm{H}_{2} \mathrm{SO}_{4}$ (at $\left.5.441 \mathrm{M}\right)=\mathrm{H}_{2}(1 \mathrm{~atm}$.) + $2 \mathrm{O}_{2}$ (1 atm. $)+\mathrm{S}_{\mathrm{rh}}$.

To express this heat effect as a temperature function we make use of the following molal heat-capacity values: ${ }^{13}$ for $\mathrm{H}_{2}, C_{\mathrm{p}}=6.50+0.0009 \mathrm{~T}$; for $\mathrm{O}_{2}, C_{\mathrm{p}}=6.50+0.0010 T$; for $\mathrm{S}_{\mathrm{rb}}, C_{\mathrm{p}}=4.12+0.0047 \mathrm{~T}$; and for the partial molal heat capacity of $1 \mathrm{H}_{2} \mathrm{SO}_{4}$ in $5.441 \mathrm{M}$ solution (at mole fraction $0.0893), C_{\mathrm{p}}=15.86$. The valies of $\Delta H$ and $\Delta F$ at any temperature $T$ for this reaction are therefore given by the expressions: $\Delta H=200,040+$ $7.76 T+0.0038 T^{2} ; \Delta F=200,040-7.76 T \ln T-0.0038 T^{2}+I T$. From the value of $\Delta F=169,850 \mathrm{cal}$. as derived above for this reaction at $T=353.1^{\circ} \mathrm{K}$. the value of $I$ is calculated to be -38.62 . Solving this equation for $\Delta F$ at $298.1^{\circ} \mathrm{K}$. we find its value to be $175,010 \mathrm{cal}$, which with negative sign is the free energy content of $1 \mathrm{H}_{2} \mathrm{SO}_{4}$ in $5.441 \mathrm{M}$ solution.

In order to compare this result with the values of the free energy of sulfuric acid previously derived, it is best to recalculate it to hypothetical $1 M$. This may be done with the aid of the activity values derived by Lewis and Randall. ${ }^{14}$ By interpolation from a plot of their values we find for the molality 5.441 an ion-activity coefficient of 0.237 . Since this coefficient $\gamma$ is defined ${ }^{15}$ by them by the equation $4 m^{3} \gamma^{3}=a_{\mathrm{H}}^{2} a_{\mathrm{SO}_{4}}=$ $a_{\mathrm{H}_{2} \mathrm{SO}_{4}}$ where the $a$ 's represent the activities at molality $m$, we find the activity of the sulfuric acid at $5.441 M$ to be $4 \times(5.441)^{3} \times(0.27)^{3}$ or 13.1. Now, by subtracting the value $298.1 R \ln 13.1$, which is equal to 1525 cal., from $-175,010$ cal. we find $-176,535$ cal. as the free energy of $1 \mathrm{H}_{2} \mathrm{SO}_{4}$ at $25^{\circ}$ at hypothetical $1 M$ (that is, when $\mathrm{H}^{+}$is $1 M$ and $\mathrm{SO}_{4}=$ is $1 M$ and these ions have activity-coefficient unity). ${ }^{16}$

This value agrees closely with the "provisional value" $-176,500$ adopted by Lewis and Randall. ${ }^{17}$ This confirmation was desirable, since without

12 Ref. 2, p. 95.

${ }^{13}$ Ref. 2 , pp. 80,86 and 531 .

14 Ref. 2, p. 357.

15 Ref. 2, p. 328.

${ }^{16}$ It may be noted that an error of $1 \%$ in the estimated activity of the acid at 5.441 $M$ makes an error of only 20 calories in the result.

${ }^{17}$ Ref. 2, p. 554 . 
giving the separate valtes the authors state that their result is the average, obtained by three independent methods, of values differing by $1000 \mathrm{cal}$.

The uncertainty in our value due to error in the measurements at $80^{\circ}$ probably does not exceed 240 cal., which is the average deviation of the three independent determinations from the mean. It is impracticable, however, to estimate the error involved in the correction of about 5000 cal. in recalculating the result to $25^{\circ}$ with the aid of the heat data, or the incertainty introduced by neglecting the activation effect of the hydriodic acid present with the sulfuric acid in the equilibrium mixtures. Whatever be the accuracy of our final value, it is hoped that the results presented in this research may facilitate a more extensive investigation by the same method, which lack of time prevented us from carrying out.

\section{The Reduction Potentials of Sulfur Compounds at $25^{\circ}$}

Now that the free energy of the sulfate ion has been determined with greater certainty, it seems worth while to compute and tabulate the freeenergy decreases and the corresponding molal reduction potentials for the electronic reactions that are of direct practical importance in determining the oxidation-reduction behavior of sulfur compounds in aqueous solution. This has been done from the free energies by combining the new value $(-176,540$ cal.) for the sulfate ion with the free energies of other sulfur compounds given by $\mathrm{L}_{\text {ewis }}$ and Randall. ${ }^{18}$ The corresponding reduction potentials have been found by multiplying the resulting free energies by 4.182 (to reduce them to joules) and then dividing by 96,494 and by the number of faradays involved in the electronic reaction.

The results are presented in Table IV, of which the headings are in the main self-explanatory. The electronic reaction is understood to involve as its counterpart the reaction $\mathrm{N}\left(\mathrm{H}^{+}=1 / 2 \mathrm{H}_{2}\right)$ for which the free-energy change is regarded as zero and to imply that all the substances, except the (solid) sulfur and (liquid) water, are at $1 \mathrm{M}$.

\section{TABLE IV}

Molal Rfiduction PotejNTtals of SUlfut and its Compounds at $25^{\circ}$

$\begin{array}{llcr}\quad \text { Reduced state } & \begin{array}{c}\text { Oxidized state } \\ \mathrm{H}_{2} \mathrm{~S}+2 \oplus \text { Free-energy } \\ \text { decrease }\end{array} & \begin{array}{c}\text { Reduction- } \\ \text { potential }\end{array} \\ \mathrm{H}_{2} \mathrm{~S}+2 \mathrm{H}_{2} \mathrm{O}(1)+6 \oplus & -6,490 & -0.141 \\ \mathrm{H}_{2} \mathrm{~S}+4 \mathrm{H}_{2} \mathrm{O}(1)+8 \oplus & \mathrm{SO}_{2}+6 \mathrm{H}^{+} & -49,840 & -.360 \\ \mathrm{~S}(\mathrm{~s})+2 \mathrm{H}_{2} \mathrm{O}(1)+4 \oplus & \mathrm{SO}_{4}^{=}+10 \mathrm{H}^{+} & -56,190 & -304 \\ \mathrm{~S}(\mathrm{~s})+4 \mathrm{H}_{2} \mathrm{O}(1)+6 \oplus & \mathrm{SO}_{2}+4 \mathrm{H}^{+} & -43,350 & -.470 \\ \mathrm{SO}_{2}+2 \mathrm{H}_{2} \mathrm{O}(1)+2 \oplus & \mathrm{SO}_{4}=+8 \mathrm{H}^{+} & -49,700 & -.359 \\ & \mathrm{SO}_{4}=+4 \mathrm{H}^{+} & -6,350 & -.138\end{array}$

Some interesting conclusions to be drawn from these results may be pointed out. When all the substances involved are at $1 M$ the reducing powers of hydrogen sulfide and sulfur dioxide are nearly the same, though

18 Ref. 2 , p. 608. 
that of the former becomes relatively greater at higher hydrogen-ion concentrations. Sulfuric acid should from the equilibrium standpoint be capable of reduction to sulfur and hydrogen sulfide by very mild reducing agents, the fact that this does not occur in practice being doubtless due to marked passivity or slow reactivity of the sulfate ion. Any reducing agent strong enough to reduce sulfuric acid to sulfurous acid should be capable of reducing it completely to hydrogen sulfide, thus showing that it is impossible to realize at $25^{\circ}$ stable equilibrium conditions between these two acids. Sulfuric or sulfurous acid may, however, be reduced to sulfur, without producing hydrogen sulfide; but the formation of the latter is. favored by large hydrogen-ion concentration.

\section{Summary}

The equilibritum conditions of the reaction $\mathrm{H}_{2} \mathrm{SO}_{4}(5.4-6.8 \mathrm{M})+6 \mathrm{HI}-$ $(0.4-1.0 M)=3 \mathrm{I}_{2}+4 \mathrm{H}_{2} \mathrm{O}+\mathrm{S}_{\mathrm{rh}}$ at $80^{\circ}$ have been determined. The electromotive force of cells consisting of the equilibrium mixtures and a platinum electrode as one half-cell, and of sulfuric acid at the same molality, hydrochloric acid at the same concentration as the hydriodic acid, and of a hydrogen electrode as the other half-cell, have also been measured at $80^{\circ}$. By combining these data the partial free energy of $1 \mathrm{H}_{2} \mathrm{SO}_{4}$ at $5.441 \mathrm{M}$ was calculated to be $-169,850 \mathrm{cal}$. at $80^{\circ}$. With the aid of known heat data the corresponding value at $25^{\circ}$ was computed to be $-175,010$ cal.

By means of the activity data of Lewis and Randall the free energy of $1 \mathrm{SO}_{4}=$ at hypothetical $1 \mathrm{M}$ at $25^{\circ}$ was found to be $-176,540$ cal., thus confirming the provisional value $-176,500$ cal. derived by Liewis and Randall.

By combining this new value for the free energy of sulfate ion with the values given by Lewis and Randall for other sulfur compounds, the reduction potentials of various combinations that are of much practical significance in determining the oxidation chemistry of stlfur compounds in solution have been worked out and tabulated (see Table IV).

Pasadena, Californita 